\title{
Recycling Polyurethane Materials to Improve Properties of Wood Composite Panels
}

\author{
Xiaosheng Liu ${ }^{1}$, Yanfang Pang ${ }^{1}$, Tongtong Cui ${ }^{1}$, Yan $\mathrm{Li}^{1}$, Enhua $\mathrm{Xi}^{1}$, Xin Liu ${ }^{1}$, Qi Li ${ }^{1,}$, \\ Hui Wan ${ }^{2, *}$, An Mao ${ }^{1,3}$, * \\ ${ }^{1}$ Key Laboratory of State Forestry Administration for Silviculture of the Lower Yellow River, Shandong Agricultural University, Taian, China \\ ${ }^{2}$ College of Material and Engineering, Southwest Forestry University, Kunming, China \\ ${ }^{3}$ Beijing Key Laboratory of Wood Science and Engineering, Beijing Forestry University, Beijing, China
}

Email address:

wonderfulliqi2364@126.com (Qi Li),wanandwan@yahoo.com (Hui Wan),dannymaoan@126.com (An Mao)

${ }^{*}$ Corresponding author

\section{To cite this article:}

Xiaosheng Liu, Yanfang Pang, Tongtong Cui, Yan Li, Enhua Xi, Xin Liu, Qi Li, Hui Wan, An Mao. Recycling Polyurethane Materials to Improve Properties of Wood Composite Panels. American Journal of Agriculture and Forestry. Vol. 7, No. 4, 2019, pp. 146-150. doi: 10.11648/j.ajaf.20190704.14

Received: July 12, 2019; Accepted: August 4, 2019; Published: August 15, 2019

\begin{abstract}
The objective of this study was to investigate the feasibility of using polyurethane (PU) foam wastes obtained from automobile shredder residue (ASR) in wood composite panel (fiberboard) production. PU foam wastes from ASR were picked by hand, cleaned by water and acetone, grounded into powders of two sizes (60 mesh and 120 mesh), and dried to remove moisture. The PU powders were characterized by stereomicroscope and then partially replaced pMDI resin at percentages of $10 \%, 20 \%, 30 \%, 40 \%$, and $50 \%$ (based on the weight of pMDI resin). The PU powders were mixed with wood fibers to make fiberboards. The results showed that the addition of PU powders increased both the physical and mechanical properties of fiberboards. At replacing percentages from 5\% to 30\%, the properties of fiberboards increased. However, further increase of replacing percentages (from 30\% to 50\%) resulted in lower properties of fiberboard. When observed at a magnification of 125 times by a stereomicroscope, PU powders of 60 mesh had more foam features while PU powders of 120 mesh had more particle features. The fiberboards bonded by pMDI resin and PU powders of 120 mesh had better water resistance and mechanical properties than those bonded by pMDI and PU powders of 60 mesh. The use of PU powders in fiberboard production provided a new possible way of recycling PU foam wastes. The fiberboard has advantages of formaldehyde-free, better water resistance, higher mechanical properties, and lower material cost.
\end{abstract}

Keywords: Polyurethane Foam Waste, Recycle, Dipheny Lmethane Diisocyanate, Fiberboard

\section{Introduction}

Polyurethane (PU) refers to a group of polymers that contain - $\mathrm{CO}-\mathrm{NH}-$ group in the primary molecule chains. PU materials are widely used in various applications including building, transportation, electronic, clothing, sports, and etc. The amount of disposed PU wastes is also huge each year. In China, about 6 million vehicles reach the end of their service lives annually, generating automobile shredder residue (ASR) of 9 million tons. $12-16 \%$ of the ASR wastes are PU foam materials [1]. A Chinese professional standard (SB/T 11160-2016) "Technical Specification for Crushing of Waste Vehicles" was released in the year of 2016. According to the standard, after crushing and sorting, the comprehensive recovery rate of renewable resources should not be less than $90 \%$. The increasing use of the PU foam materials in the automobile made vehicles lighter, faster, and more economic, but also created a great challenge. Currently, only a small fraction of the PU foams is recycled, most of them go to the landfill creating an environment burden [2]. Therefore, it is required to find ways to recycle $\mathrm{PU}$ foam wastes appropriately.

The wood panel industry is developing fast in China. Urea-formaldehyde (UF) resin is mainly used in plywood, particleboard, and fiberboard production. However, UF-bonded panels have problems of formaldehyde release 
and poor water resistance [3-5]. Currently, there are two primary research directions: one is to modify UF and other formaldehyde-based resins for improved water resistance and lowered formaldehyde release; the other direction is to replace formaldehyde-based resins with other adhesives containing no formaldehyde [6-8]. Polymeric Diphenylmethane diisocyanate (pMDI) resin can be used as particleboard and fiberboard binders [9]. Compared with formaldehyde-based thermosetting synthetic resins, pMDI has advantages of high bonding strength, good water resistance, and no formaldehyde release from bonded wood panels. However, it is petroleum derived and the price of pMDI resin is 5-7 times higher than that of UF resin.

The applications of PU foam materials in wood panel production are seldom reported [10, 11]. Mansouri and Pizzi [12] added flexible PU foam powders into UF resins to make plywood and particleboard. It was found that PU powders served as active fillers or extenders to improve both the dry and wet strength of UF bonds. Mao et al. [13] mixed pMDI with recycled rigid PU foam powders at different ratios for particleboard fabrication. The internal bond strength of particleboard was improved when replacing $5 \%$ to $15 \%$ of pMDI with rigid PU powders.

The objective of this study was to investigate the feasibility of using PU foam wastes in wood composite panel (fiberboard) production. The study results could provide a theoretical basis and scientific guidance for the rational recycling process and application technology development of waste PU materials.

\section{Materials and Methods}

\subsection{Materials Preparation}

Flexible PU foams were obtained from local waste vehicle recycling company in Taian, Shandong province. They were handpicked from ASR. The color of the foams was light brown (Figure 1). Some rubber, wood, fibers, paper, glass and others that in the PU were removed and the foams were washed by water and then by acetone (obtained from Sinopharm Group Co. Ltd, Beijing). The foams were then air-dried and grounded into powders with sizes of 60 and 120 meshes by a grounding machine (Laboratory Mill, Model WQM, Jingcheng Chemical Machinery Co. Ltd, Jiangyin). The PU foam powders were then dried in an oven at $100^{\circ} \mathrm{C}$ for $1 \mathrm{~h}$ (Figure 2).

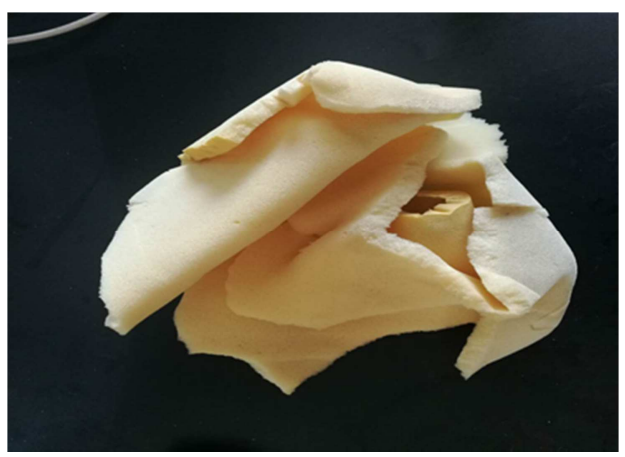

Figure 1. Polyurethane foam wastes.

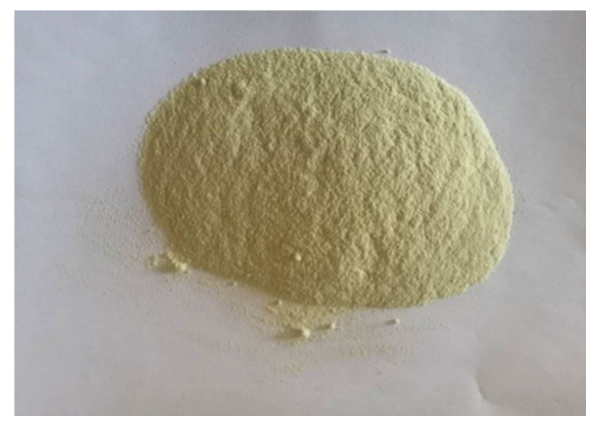

Figure 2. Polyurethane powders.

The pMDI (WANNATE PM-200) with the NCO content of $30.5 \%-32 \%$ and viscosity of $150-250 \mathrm{mPa} \cdot \mathrm{s}\left(25^{\circ} \mathrm{C}\right)$ was obtained from Wanhua Chemical Group Co., Ltd, Shandong, China. Mixed pine wood fibers with an original moisture content of $12 \%-15 \%$ were obtained from Toroyal Wood Products Corp., Shandong, China.

The micromorphology of PU powders with sizes of 60 mesh and 120 mesh was observed using a SMZ 1500 stereomicroscope (Nikon Imaging Japan Inc., Tokyo) with a magnification of 112.5 times. The SPOT ${ }^{\mathrm{TM}}$ software was used to analyze the pictures.

\subsection{Stereomicroscope}

The micromorphology of PU powders with sizes of 60 mesh and 120 mesh was observed using a SMZ 1500 stereomicroscope (Nikon Imaging Japan Inc., Tokyo) with a magnification of 112.5 times. The SPOTTM software was used to analyze the pictures.

\subsection{Fiberboard Manufacturing}

Wood fibers were first dried to the moisture content of $6.0 \%$ and put into a laboratory rotating blender. Then, the PU powders were calculated and put into the blender. The pMDI resin was pumped via a tube and sprayed on the rotating fibers and powders within a blending time of about $12 \mathrm{~min}$. The blended fibers were weight and hand-laid on a stainless steel caul plate in a wooden formatting box of $580 \mathrm{~mm} \times 580 \mathrm{~mm}$ to obtain a uniform mat. After removing the box, another stainless steel caul plate was put on the mat and the mat was then transferred to a laboratory hot press. The hot press time and temperature were $5.0 \mathrm{~min}$ and $170^{\circ} \mathrm{C}$, respectively. Two boards were made for each resin composition. After pressing, the boards were conditioned at $20^{\circ} \mathrm{C}$ and 60 percent relative humidity for 1 week. The experimental design and fiberboard manufacturing parameters were shown in Table 1.

Table 1. Experimental design and fiberboard manufacturing parameters.

\begin{tabular}{ll}
\hline Replacing percentages of PU powders (\%) & $0,10,20,30,40,50$ \\
Size of PU powders (mesh) & 60,120 \\
Moisture content of fibers (\%) & $6 \%$ \\
Structure of fiberboard & Uniform (one layer) \\
Board dimension (mm) & $550 \times 550 \times 12$ \\
Resin application rate (\%) & 5 \\
System pressure (atm) & 1 \\
FP powder size (mm in diameter) & 1 \\
FP powder moisture content (\%) & 0 \\
\hline
\end{tabular}




\subsection{Physical and Mechanical Testing of Fiberboards}

Internal bond (IB), modulus of rupture (MOR) and modulus of elasticity (MOE) were tested on a CMT 4104 universal testing machine (MTS System Corporation, MN). Water-soak thickness swell (TS) and water absorption (WA) values were measured in a $20^{\circ} \mathrm{C}$ water bath according to Chinese National Standard GB/T 17657-2013. Eight IB samples, three bending samples and two water-soak samples were tested from each board. Density of each test sample was obtained by dividing weight by volume.

\section{Results and Discussion}

\subsection{Characterization of the PU Foams}
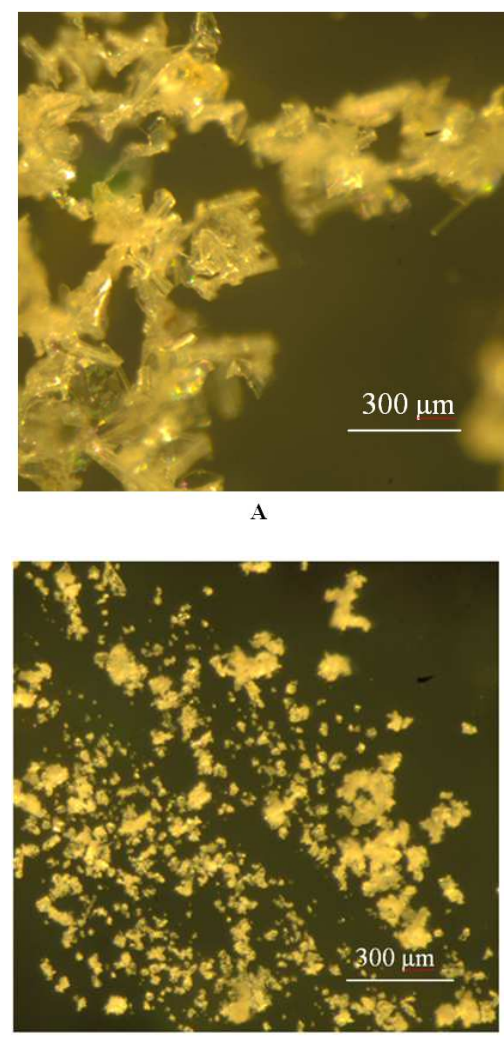

Figure 3. The micromorphology of PU powders (112.5).

The original color of PU foams was light brown. After the PU foams were washed by water and acetone, dried, and grounded into powders, the color turned to light yellow, and a weight loss of $10-15 \%$ was obtained. The weight loss could be from water-soluble and acetone-soluble liquids, and some volatile compounds.

Figure 3 shows the micromorphology of PU powders of two sizes (60 mesh and 120 mesh) observed by a stereomicroscope with a magnification of 112.5 times. Figure 3A shows micromorphology of PU powders of 60 mesh. The powders exhibited obvious foam features with irregular surfaces, plenty of pores and wrinkles inside, and compressibility. The powders in figure 3B (120 mesh) exhibited features more like particles.

\subsection{Internal Bond}

Fiberboard IB data are shown in Table 2. There were variations among boards made and among different samples from the same boards. IB data were presented with average value with sample standard deviation information. Since there were only three samples for MOE/MOR test, two samples for TS/WA tests, these data were presented with average value without sample standard deviation information. The related sample density information was listed for reference purpose.

IB bond strength reflects the quality of bonds between wood fibers in boards. Higher IB value usually indicates better bond quality. As shown in Table 2, IB of fiberboard containing PU powders was higher than that of fiberboard without PU powders (0.69 MPa). After replacing 10\%, 20\%, and 30\% pMDI resin with PU powders of 120 mesh, IB values increased to $0.91,1.07$, and $1.25 \mathrm{MPa}$, respectively. When the replacing percentage further increased to $40 \%$ and $50 \%$, IB value decreased to 0.82 and $0.55 \mathrm{MPa}$, respectively. After replacing pMDI resin with PU powders of 60 mesh, the trend of IB variation was similar, but the general IB strength was lower.

Table 2. Internal bond test results.

\begin{tabular}{llll}
\hline $\begin{array}{l}\text { PU Replacing } \\
\text { percentage } \mathbf{( \% )}\end{array}$ & $\begin{array}{l}\text { PU powder } \\
\text { size (mesh) }\end{array}$ & $\begin{array}{l}\text { Density } \\
\left(\mathbf{g} / \mathbf{m}^{\mathbf{3}}\right)\end{array}$ & $\begin{array}{l}\text { Internal bond } \\
(\mathbf{M P a})\end{array}$ \\
\hline 0 & - & 0.741 & $0.69(0.05)$ \\
10 & 120 & 0.742 & $0.91(0.08)$ \\
20 & 120 & 0.751 & $1.07(0.11)$ \\
30 & 120 & 0.750 & $1.25(0.09)$ \\
40 & 120 & 0.755 & $0.82(0.07)$ \\
50 & 120 & 0.749 & $0.55(0.02)$ \\
10 & 60 & 0.753 & $0.72(0.07)$ \\
20 & 60 & 0.748 & $0.79(0.03)$ \\
30 & 60 & 0.752 & $0.85(0.07)$ \\
40 & 60 & 0.754 & $0.67(0.04)$ \\
50 & 60 & 0.747 & $0.37(0.02)$ \\
\hline
\end{tabular}

Note: Values in parenthesis are sample standard deviations

In fiberboard manufacturing, many factors influence the mechanical strength of board, such as mat moisture content, hot press schedule, resin type and application rate, and board thickness. After pMDI was partially replaced by PU powders, the PU powders mixed with fibers and participated in the hot pressing of boards. Under certain high temperature, PU powders might become thermoplastic and behave as adhesives [14]. Moreover, some reactions might happen between -NCO groups in pMDI and -NH- groups in PU powders [15]. These reactions might result in the increase of the cross link density of cured resins which would contribute to the cohesion strength of cured pMDI resins. In these cases, the PU powders would help fiber bonding and increase IB strength. The PU powders of smaller size melt easier and had larger specific surface area. These could increase contact area between PU powders and fibers, and contribute to a better bonding. Therefore, fiberboards containing PU powders of smaller sizes had higher IB values. As the replacing percentage of PU powders increased, more powders could participate in and help bonding. However, when the replacing percentage was too high $(40 \%$ and $50 \%)$, the amount of pMDI became 
insufficient and too many powders in pMDI resin might disturb the uniformity of cured resin and spoil the bonding, resulting in a lower IB strength. Therefore, considering the IB strength test results, PU powder size of 120 mesh and replacing percentage of around $30 \%$ are desirable parameters.

\subsection{Modulus of Rupture and Modulus of Elasticity}

Bending performance is to test the maximum compressive strength of wood-based panels when they are bent to break. As shown in Table 3, MOR of fiberboard containing PU powders was higher than that of fiberboard without PU powders (34 $\mathrm{MPa}$ ). After replacing $10 \%, 20 \%$, and $30 \%$ pMDI resin with PU powders of 120 mesh, MOR values increased to 41, 52, and $59 \mathrm{MPa}$, respectively. When the replacing percentage further increased to $40 \%$ and $50 \%$, MOR value decreased to
39 and $31 \mathrm{MPa}$, respectively. After replacing pMDI resin with PU powders of 60 mesh, the trend of MOR variation was similar, but the general MOR strength was lower. The MOE results are similar to MOR results with maximum value occurred at PU replacing percentage of $30 \%$.

IB mainly reflects the bond strength of fiberboard, while MOR and MOE test results not only reflect the bonding, but also reflect the influences brought by other factors, such as fiber distribution and direction in board, hot press schedule, and etc. PU powders could bond fibers and pMDI to improve bonding as discussed above. Meanwhile, they could fill the gaps between fibers and increase the density of board (as indicated from density measurement results), especially the surface density of the board, which determines MOR and MOE values for the greater part.

Table 3. Modulus of rupture and modulus of elasticity tests results.

\begin{tabular}{lllll}
\hline PU Replacing percentage (\%) & PU powder size (mesh) & Density $\left(\mathbf{g} / \mathbf{m}^{3}\right)$ & MOR $(\mathbf{M P a})$ & MOE $(\mathbf{M P a})$ \\
\hline 0 & - & 0.745 & 34 & 6231 \\
10 & 120 & 0.751 & 41 & 6655 \\
20 & 120 & 0.750 & 52 & 7010 \\
30 & 120 & 0.756 & 59 & 7210 \\
40 & 120 & 0.754 & 39 & 6250 \\
50 & 120 & 0.748 & 31 & 5811 \\
10 & 60 & 0.753 & 39 & 6317 \\
20 & 60 & 0.752 & 41 & 6522 \\
30 & 60 & 0.749 & 28 & 6587 \\
40 & 60 & 0.755 & 21 & 5387 \\
50 & 60 & 0.751 & 5099 \\
\hline
\end{tabular}

\subsection{Thickness Swell and Water Absorption}

TS value refers to the thickness incensement percentage of board sample after the sample was immersed into water of $25 \mathrm{oC}$ for $24 \mathrm{~h}$. WA value refers to the weight incensement percentage of board sample after the sample was immersed into water of 25 $\mathrm{oC}$ for $24 \mathrm{~h}$. These two values are normally used to evaluate the water resistant performance of boards. Usually, lower TS and WA values indicate better water resistance. As shown in table 4, both the TS and WA values decreased after PU powders were added into boards indicating that adding PU powders could improve water resistant performance of fiberboards. The TS and WA values of boards bonded by pure pMDI resin were $16.1 \%$ and $26.9 \%$, respectively. After partially replacing pMDI with PU powders of 120 mesh, the TS values decreased first (from 15.2\% to $14.5 \%$ ) and then increased (from $14.5 \%$ to $16.9 \%$ ). The WA values decreased first (from $25.6 \%$ to $25.1 \%$ ) and then increased (from $25.1 \%$ to $29.1 \%$ ). The lowest TS and WA values are $14.5 \%$ and $25.1 \%$, obtained at PU replacing percentage of $30 \%$. After replacing pMDI resin with PU powders of 60 mesh, the trends of TS and WA variations were similar, but the general values were lower. These results indicated that adding an appropriate amount of PU powders improved water resistance of fiberboard, but too many PU powders could lower the water resistance.

TS and WA values are influenced by various factors, such as wood species, fiber dimension, resin type, resin application rate, resin spraying, board density, and hot press condition. PU powders have the nature of water hydrophobicity. Therefore, the addition of a certain amount of PU powders could help increase the water resistance of fiberboard. However, the PU foam materials could also absorb water and swell. If too many PU powders were added into board, PU powders would swell and disturb resin layer resulting decreased water resistance.

Table 4. Thickness swell and water absorption tests results.

\begin{tabular}{lllll}
\hline PU Replacing percentage (\%) & PU powder size (mesh) & Density $\left(\mathbf{g} / \mathbf{m}^{\mathbf{3}}\right)$ & TS (\%) & WA (\%) \\
\hline 0 & - & 0.742 & 16.1 & 26.9 \\
10 & 120 & 0.745 & 15.2 & 25.6 \\
20 & 120 & 0.744 & 14.8 & 25.1 \\
30 & 120 & 0.746 & 14.5 & 25.1 \\
40 & 120 & 0.750 & 16.1 & 28.5 \\
50 & 120 & 0.721 & 16.9 & 29.1 \\
10 & 60 & 0.748 & 15.5 & 26.1 \\
20 & 60 & 0.752 & 15.4 & 26.5 \\
30 & 60 & 0.745 & 15.0 & 25.8 \\
40 & 60 & 0.756 & 17.1 & 28.9 \\
50 & 60 & 0.758 & 19.5 & 33.3 \\
\hline
\end{tabular}




\section{Conclusion}

In this study, PU foam wastes from ASR were picked by hand, cleaned by water and acetone, grounded into powders of two sizes (60 mesh and 120 mesh), and dried to remove moisture. The PU powders were characterized by stereomicroscope and then used to replacing pMDI resin. The replacing percentages were $10 \%, 20 \%, 30 \%, 40 \%$, and $50 \%$, based on the weight of pMDI resin. Fiberboards were made and tested. The results showed that the addition of PU powders increased the IB, MOR, and MOE values and decreased TS and WA values of fiberboard. At replacing percentages of $30 \%$, the fiberboard had the best physical and mechanical performances. However, further increase of replacing percentages $(40 \%$ and $50 \%)$ resulted in lower properties of fiberboard. When observed at a magnification of 125 times, PU powders of 60 mesh size had more foam features while PU powders of 120 mesh size had more particle features. The fiberboards bonded by pMDI resin and PU powders of 120 mesh had better water resistance and mechanical properties than those bonded by pMDI and PU powders of 60 mesh.

In summary, the addition of PU powders into pMDI resin provided a new possible way of recycling PU foam wastes in wood composite panel production. The fiberboard composed of wood fibers and PU powders, and bonded by pMDI resin has advantages of environmental-friendly (formaldehyde-free), higher water resistant and mechanical performance, and lower production cost. The future study will be focused on the reaction mechanism between pMDI, $\mathrm{PU}$, and wood as well as optimization of hot pressing parameters in fiberboard production.

\section{Author Contributions}

The Manuscript was written through contributions of all authors. All authors have given approval to the final version of the manuscript. Xiaosheng Liu and Yanfang Pang contributed equally and should be considered as co-first authors.

\section{Conflicts of Interest}

The authors declare no competing financial interest.

\section{Acknowledgments}

The authors are grateful for the supports of the Fundamental Research Funds for the Central Universities (Project No. BJFUKF201912), Youth Foundation of Shandong Natural Science Foundation (Project No. ZR2017QC006), Scientific Research Project of Colleges and Universities in Shandong Province (Project No. J17KA147) and National Student Innovation and Entrepreneurship Training Program (Project No. 201810434013).

\section{References}

[1] F. Ni, and M. Chen, Studies on pyrolysis and gasification of automobile shredder residue in China. Waste Management \& Research: the Journal of the International Solid Wastes and Public Cleansing Association, ISWA 32 (10), 980-987, 2014.

[2] J. Haydary, and S. Dalibor, Characterization of automobile shredder residue for purpose of its thermal conversion. Journal of Solid Waste Technology and Management, 41 (1), 41-49, 2015.

[3] A. Mao, E. B. Hassan, and M. G. Kim, The effects of adding melamine at different resin synthesis points of low mole ratio urea-melamine-formaldehyde (UMF) resins. BioResources, 8 (4), 5733-5748, 2013.

[4] J. Luo, J. Zhang, Q. Gao, A. Mao, and J. Li, Toughening and enhancing melamine-urea-formaldehyde resin properties via in situ polymerization of dialdehyde starch and microphase separation. Polymers, 11, 1167-1185, 2019.

[5] Q. Wang, N. Wu, X. Li, W. Hui, H. Lei, G. Du, Z. Wu, and S. Liu, Improving the performance of Eucalyptus wood particle board panels with low free formaldehyde emission urea-formaldehyde resin using Pectinase enzyme pre-treatments. BioResources, 13 (2), 2996-3004, 2018.

[6] R. Wang, Z. Zhang, R. Chen, L. Zhao, C. Wang, and F. Chu, Synthesis of phenol-urea-formaldehyde resin and its reaction mechanism. Chemistry and Industry of Forest Products, 38 (1), 101-109, 2018.

[7] Y. Pang, W. Xu, Q. Li, C. Li, and A. Mao, Research progress of bio-based wood adhesives. China Forest Products Industry, 45 (4), 3-7, 2018.

[8] Q. Gao, C. Liu, J. Luo, X. Li, L. Chen, W. Wang, and J. Li, Effects of resin open time and melamine addition on cold pre-pressing performance of a urea-formaldehyde resin. European Journal of Wood and Wood products, 76 (4), $1253-1261,2018$

[9] Q. Li. M. Li, C. Chen, G. Cao, A. Mao, and H. Wan, Adhesives from polymeric methylene diphenyl diisocyanate resin and recycled polyols for plywood. Forest Products Journal, 67 (3/4), 275-282, 2017.

[10] H. Bene, R. Cerna, A. Durackova, and P. Latalova, Utilization of natural oils for decomposition of polyurethanes. Journal of Polymers and the Environment, 20 (1), 175-185, 2012.

[11] Q. Li, M. Li, C. Cheng, G. M. Cao, A. Mao, and H. Wan, Adhesives from Polymeric Methylene Diphenyl Diisocyanate Resin and Recycled Polyols for Plywood. Forest Products Journal, 67 (3/4), 275-282, 2017.

[12] H. R. Mansouri, A. Pizzi, Recycled micronized polyurethane powders as active extenders of UF and PF wood panel adhesives. Holz als Roh- und Werkstoff, 65 (4), 293-299, 2007.

[13] A. Mao, R. Shmulsky, Q. Li, and H. Wan, Recycling polyurethane materials: A comparison of polyol from glycolysis with micronized polyurethane powder in particleboard applications. BioResources, 9 (3), 4253-4265, 2014. 
[14] P. Berthevas, G. Santoro, R. Wevers, H. Gruenbauer, and A. Pizzi, Recycled polyurethane foam powder can be used in conjunction with pMDI in particle boards to obtain the required properties while reducing costs. $9^{\text {th }}$ European Panel Products Symposium, Llandudno, Wales, UK, 40-47, 2005.
[15] A. Pizzi, Synthetic adhesives for wood panels: Chemistry and Technology-a critical review. Reviews of Adhesion \& Adhesives, 2 (1), 85-125, 2014. 